\title{
Strabismus Surgery in Children: The Prospects for Binocular Single Vision
}

\author{
H. E. WILLSHAW and J. KEENAN \\ Birmingham
}

\begin{abstract}
Summary
The restoration or maintenance of useful binocular single vision (BSV) represents the ideal outcome in the management of a squinting child. However, in planning such management it is essential to have a clear appreciation of the likelihood of attaining that goal, and what factors will help in its attainment.

Using both a literature review and some preliminary information from our own patient database we examine the prospects for BSV in different strabismus groups. We also discuss the techniques available to allow prediction of which children are candidates for the development of BSV following squint correction.
\end{abstract}

The ideal outcome in the management of a squinting child is the restoration or establishment of binocular single vision (BSV) and motor fusion. With these goals secured the strabismus surgeon can look forward to the long-term stability of the surgical result. If these objectives cannot be achieved then the natural progression towards divergence with increasing age ${ }^{1}$ will tend to give rise to increasing numbers of cosmetically unsatisfactory results and to late surgical correction of consecutive exotropia with the attendant risk of intractable diplopia.

Our surgical objectives, be they orthophoria, deliberate undercorrection or deliberate overcorrection should, therefore, be guided by the expectation of useful BSV resulting from treatment. This review examines some of the theoretical considerations relating to different types of strabismus, and supplements those considerations with information obtained from interrogation of our own patient database. The database consists of consecutive patients followed for at least five years, and while currently small, provides useful additional information. We also examine some of the ways in which the likelihood of developing BSV may be predicted in any individual child.

\section{Esotropia}

(a) Congenital/Early Infantile

An extensive literature on this group of patients has flourished, largely because it represents a discrete, easily identified cohort. The major discussion centres on the timing of surgical intervention, the prospects for BSV and the quality of BSV obtained. ${ }^{2.3,4.5}$ When evaluating such reports care must be exercised in assessing the different results reported using different tests of BSV. Particularly, as Harcourt and Mein point out, the presence of motor fusion in the early postoperative period does not necessarily correlate with stable BSV later. ${ }^{6}$ Nonetheless, it does appear that a significant proportion of such children will develop microtropia with stereopsis if corrected to within 10 prism dioptres by two years of age, ${ }^{7}$ and that this outcome greatly reduces the risk of consec- 
utive exotropia. ${ }^{8}$ Since there is no pressing anaesthetic argument for delaying strabismus surgery beyond this age, it has been our policy since 1982 to perform the initial surgery for early onset esotropia at 14 to 18 months of age, so that further procedures (necessary in $33 \%$ to $45 \%$ of children ${ }^{9,10}$ ) can be completed before the second birthday. As well as affording an opportunity for the development of BSV, early surgery may also improve the general performance of the child, an observation often made by parents, and recently quantified. ${ }^{11}$

Amongst a group of patients with esotropia present before six months of age, will be other entities masquerading as congenital esotropia. Duane's Retraction syndrome, bilateral sixth nerve palsies and the nystagmus blocking syndrome are identified at the initial assessment. The child with early onset accommodative esotropia ${ }^{12}$ must also be identified (to avoid inappropriate surgery) and any hypermetropic correction of +2.00 dioptres or more should be given to assess its effect. ${ }^{13}$ Similarly, the neurologically damaged child with early onset esotropia needs to be recognised, since the behaviour of the squint may be quite different ${ }^{14}$ and because the prospects for useful BSV are so much poorer ${ }^{15}$ that delaying surgery to allow complete stability of the deviation is justifiable.

Results from our database on this group of children are shown in Table I. Only one child operated on after the age of two years developed BSV, and no child with persistent amblyopia or anisometropia achieved BSV (emphasising the need for active amblyopia therapy prior to surgical correction). For those children satisfactorily aligned by 18 to 24 months, we find $31 \%$ achieve stable BSV. Interestingly, unlike previous authors, ${ }^{8}$ we have found the presence of dissociated vertical deviation (DVD) before the age of 2 years to be incompatible with the development of worthwhile BSV.

\section{(B) Accommodative Esotropia}

Fully accommodative esotropia should not be considered in this discussion since surgery is not indicated, and full refractive correction is the treatment of choice. The parents' commonly expressed worry about long-term spectacle wear can to some extent be alleviated by pointing out the good results possible with contact lens correction as an alternative. ${ }^{16}$

\section{(C) High AC: A Ratio Esotropia}

From a practical point of view, this can be considered to exist whenever the near deviation exceeds the distance deviation by 10 prism dioptres or more. ${ }^{17}$ There may be no deviation in the distance, or alternatively an esotropia for distance which increases with accommodation. Control of the near deviation can be achieved in several ways. In the United Kingdom there is a reluctance to use bifocal spectacles as the mainstay of treatment, since it is perceived that the child may become dependent on the spectacles to avoid asthenopic symptoms in later life. ${ }^{18}$ Bifocals may, how-

Table I Preliminary database-all patients followed five years or more

\begin{tabular}{|c|c|c|c|c|c|}
\hline $\begin{array}{l}\text { Type of } \\
\text { Deviation }\end{array}$ & $\begin{array}{c}\text { Pre-op } \\
\text { Amblyopia }\end{array}$ & $\begin{array}{l}\text { Age@ } \\
\text { Surgery }\end{array}$ & $\% B S V$ & $\begin{array}{c}\% \text { BSV } \\
\text { @ } 5 \text { Years }\end{array}$ & $N$ \\
\hline $\begin{array}{l}\text { True Dist. } \\
\text { Exotropia }\end{array}$ & 0 & $\begin{array}{c}77 \text { mths } \\
(36-142)\end{array}$ & $81.8 \%$ & $72.7 \%$ & 11 \\
\hline $\begin{array}{l}\text { Sim. Dist. } \\
\text { Exotropia }\end{array}$ & 1 & $\begin{array}{l}81 \\
(62-162)\end{array}$ & $100 \%$ & $100 \%$ & 6 \\
\hline $\begin{array}{l}\text { Other Types } \\
\text { Exotropia }\end{array}$ & 3 & $\begin{array}{l}92 \\
(50-163)\end{array}$ & $45.4 \%$ & $45.4 \%$ & 11 \\
\hline $\begin{array}{l}\text { Congenital } \\
\text { Esotropia }\end{array}$ & 8 & $\begin{array}{l}33 \\
(9-88)\end{array}$ & $19.2 \%$ & $19.2 \%$ & 26 \\
\hline $\begin{array}{l}\text { High AC: A } \\
\text { Esotropia }\end{array}$ & 0 & $\begin{array}{l}52 \\
(32-73)\end{array}$ & $80 \%$ & $80 \%$ & 5 \\
\hline $\begin{array}{l}\text { Non Accomm. } \\
\text { Esotropia }\end{array}$ & 4 & $\begin{array}{l}71 \\
(29-135)\end{array}$ & $47 \%$ & $47 \%$ & 17 \\
\hline $\begin{array}{l}\text { Other Types } \\
\text { Esotropia }\end{array}$ & 4 & $\begin{array}{l}62 \\
(21-108)\end{array}$ & $37.5 \%$ & $37.5 \%$ & 8 \\
\hline
\end{tabular}


ever, be employed in a more limited way using them for a trial period to determine whether good quality BSV is established when the deviation is fully corrected. If this proves to be the case, the bifocal segment can then be gradually reduced, and surgery undertaken if the quality of BSV falls. To limit the cost of this approach, fresnel spherical lenses may be used, but whatever the form of the bifocal, it must be sufficiently high to ensure use of the bifocal segment in near viewing. In practice this means the use of an "executive" style bifocal with the upper border situated at the lower pupillary border.

Pharmacological manipulation of accommodation can be used in the same way. Since the withdrawal of Phospholine Iodide ${ }^{19}$ this involves the use of another parasympathomimetic agent, usually Pilocarpine. Parasympathomimetic agents can also be used as an indicator of BSV potential rather than in a truly therapeutic way. As with bifocals a gradual withdrawal of Pilocarpine over several weeks will occasionally reveal a cure, but more commonly indicates the functional potential in a particular patient.

Adopting an approach in which surgery follows initial identification of BSV potential would be anticipated to provide a high yield of long-term BSV results, and this is borne out in Table I. Four of five patients in this category have good quality BSV at five-year follow-up. The ideal surgical alignment in such children is probably orthophoria, though, for the more courageous, there is evidence that a small overcorrection (less than 10 prism dioptres) yields a significantly higher proportion of functional cures in acquired esotropias..$^{20,21}$

\section{(D) Partially Accommodative and Non Accommodative Esotropia}

Unfortunately, the major group of esotropes any of us will encounter falls into these two categories. It may be that many began as accommodative deviations but by remaining uncorrected for some time developed secondary features which were not correctable by removal of the accommodative component. In our group of children, however, almost half were still able to achieve BSV following surgical correction. Only one child achieving BSV had a residual deviation of 10 prism dioptres or more, whilst most of those failing to achieve BSV had larger residual angles. It may be that more aggressive surgical correction with the likelihood of a higher incidence of consecutive exotropia (rather than seeking a deliberate undercorrection in such cases) might lead to an increase in the functional cure rate.

One final comment on esotropia correction (which might equally well apply to other types of strabismus) relates to surgical planning where the anticipated outcome is BSV. In such cases all barriers to fusion must be dealt with, and this particularly applies to disorders of the cyclovertically acting muscles. Since we are incapable of generating motor torsional fusion, ${ }^{22}$ and have a limited range of vertical fusion, both these elements should be taken into consideration at the time of surgery, the torsional component will usually be dealt with by surgery to the obliques, whilst the vertical component can be predictably remedied using a transposition procedure at the time of horizontal rectus surgery. ${ }^{23}$

\section{Exotropia}

\section{(a) True and Simulated Distance Exotropia}

Though quite distinct entities, these two are grouped together because of the excellent functional cure rates to be anticipated in each. Because these children are straight for near (even if controlling an exophoria) they retain good binocular co-operation until late in the natural history of their deviation. For this reason, well timed surgical intervention will usually re-establish stable BSV.

There are conflicting recommendations in the literature. Several authors have documented the increased long-term stability of the surgical results (as gauged by the need for reoperation) when initial surgery is performed after the age of four years. ${ }^{24,25}$ Conversely, Pratt-Johnson et al advocate early surgery and document a higher functional cure rate with early surgery. ${ }^{26}$ Our approach has been to use minus lenses to maintain control of the deviation to the age of four if possible $^{27}$ (while prisms could be used in the same way, ${ }^{28}$ they appear to be rather less effective) and then proceed to surgery where necessary. With this approach, 15 of 17 children followed for five years or more show maintained BSV, 
though in seven of the children there has been an increasing exophoria over that period and one wonders whether longer review might show some loss of control. This regime is by no means sacrosanct, and the single departure from it in this group also showed an excellent result.

Such a high yield of BSV is not seen in other categories of divergence (Table I). Approximately half the children with a basic exotropia developed BSV (only one of whom was operated on before the age of four) but no child with consecutive exotropia had BSV established by its correction.

These results in the common forms of horizontal strabismus are encouraging, and suggest that the widely applied guidelines of management are realistic and appropriate. In particular, with aggressive amblyopia therapy followed by accurate and well timed ocular alignment, we can anticipate a functional outcome in the majority of exotropes and a varying number of esotropes, depending on the type of strabismus.

However, the empiric data referred to so far only tells us the probability of a BSV result in a series of children, but takes us no closer to predicting the outcome in an individual child. To do this, it is necessary to interpret information from a variety of techniques used to identify the child with BSV potential. They can be divided into established tests with which all ophthalmologists and their orthoptists will be familiar, and less well established techniques designed to address the particular problems found in the uncooperative and preverbal child.

Table II indicates some of the tests which can be used to predict the likelihood of a functional outcome following strabismus surgery. In the presence of a manifest deviation a positive response to these tests suggests the presence of anomalous retinal correspondence (ARC) which may be modified following surgery and which represents an encouraging situation. ${ }^{11}$ The least dissociating of the tests is the Lang 2 pen test which is most useful in older patients, but may be difficult to interpret in a less co-operative younger child. The Bagolini lenses unfortunately produced in our experience a BSV response when all other tests suggest the presence of suppression, and because of this, we have been cautious in interpreting this particular test and, if it is the only indication of BSV, have tended to adopt a conservative approach to surgery (i.e. deliberate small under correction in the case of esotropia). The other sensory tests are much more dissociating, particularly if performed through prisms, but if positive provide unequivocal proof of BSV potential. The prism adaptation test described by Jampol$\mathrm{sky}^{29}$ overcomes the problems of interpretation inherent in the sensory tests since it provides an easily interpreted motor response. Unfortunately to get a definitive result may take several weeks, with manipulation of the prisms, and this has deterred many from employing it on a regular basis.

In the search for a single test which can be performed at the time of preoperative assessment and which is applicable to the very young child with congenital esotropia, a number of researchers have turned to electrophysiological techniques.

Since 1978 it has been recognised that the binocular visually evoked potential (VEP) may be greater than the sum of the monocular VEPs,${ }^{30}$ and that this summation is absent in patients with suppression ${ }^{31}$ or in subjects with normal BSV which has been disrupted using a vertical prism..$^{32}$ However, it has been argued that this apparent summation may represent the excitation of two independent pools of monocularly driven neurones rather than recruitment of binocular cortical neurones. ${ }^{33}$ For this reason other investigators have used random dot stimulii.

\section{Table II Tests of potential binocular single vision}

1. Standard Tests used with or without prismatic correction

Lang 2 Pen

Bagolini Lenses

Worth 4 Dot

Stereograms

Synoptophore

2. Tests of Motor Response

15 Dioptre prism test

Prism adaptation test

3. Electrodiagnostic Tests

Summated visually evoked potential

Dynamic Random Dot correlogram

Dynamic Random element stereogram 
Two main approaches have been employed:

The dynamic random dot stereogram, in which a stereogram composed of red and green dots is generated and can be moved around the screen. The child's eye movements are then recorded and correlated to the movement of the stereogram. ${ }^{34}$ Studies with such a system have showed the early development of BSV, and also the restoration of BSV following early surgery for congenital esotropia. ${ }^{35}$

A second approach has been to use the dynamic random dot correlogram which is easier to generate and less sensitive to head movements. The Cambridge group demonstrated its value in $1980^{36}$ and more recently, Rossiter in Birmingham has used a modified technique to assess binocular function. ${ }^{37}$

To the best of our knowledge, neither of these approaches has been applied to a large clinical group, and it may well be that the time is right to undertake such a study.

There is at the moment, no test which can be relied upon accurately to identify all squinting children who have the potential to develop BSV. The traditional sensory tests are most useful but almost certainly provide an underestimate because of the dissociation involved in their performance. A reliable and easily performed electrodiagnostic assessment would be a useful addition to the techniques available.

\section{References}

${ }^{1}$ Burian HM: Hypermetropia and esotropia. J Paed Ophthalmol 1971 9: 135-9.

${ }^{2}$ Costenbader FD: Factors in the cure of squint in Strabismus Ophthal Symposium (1950), St Louis, C. V. Mosby Co.

${ }^{3}$ Riise P: Results in binocular vision in early operation in esotropia. Acta Ophthalmol 1953 31: 117-22.

${ }^{4}$ Taylor DM: Congenital strabismus: The common sense approach. Arch Ophthalmol 1967 77: 478-84.

${ }^{5}$ Hiles DA, Watson BA, Biglan AW: Characteristics of infantile esotropia following early bimedial rectus recession. Arch Ophthalmol 1980 98: 697-703.

${ }^{6}$ Mein $\mathrm{J}$ and Harcourt B: In Diagnosis and management of ocular motility disorders, Blackwell Scientific Publications (1986a): 234.

${ }^{7}$ Ing M, Costenbader F, Parks MM: Early surgery for congenital esotropia, Am J Ophthalmol 1966 61: 1419-27.

${ }^{8}$ Vasquez R, Calhoun JH, Harley RD: Development of Monofixation syndrome in congenital esotropia. J Paed Ophthalmol and Strab 1981 18: 42-4.

${ }^{9}$ Robb RM and Rodier DW: The variable clinical characteristics and course of early infantile esotropia. J Paed Ophthalmol and Strab 1988 24: 276-81.

${ }^{10}$ Ing MR: Early surgical alignment for congenital esotropia. J Paed Ophthalmol and Strab 1983 20: 11-18.

${ }^{11}$ Rogers GL, Chazan S, Fellows R, Tsou BH: Strabismus surgery and its effect upon infant development in infantile esotropia. Ophthalmology 1982 89: 479-82.

${ }^{12}$ Baker JD and Parks MM: Early onset accommodative esotropia. Am J Ophthalmol 1980 90: 11-18.

${ }^{13}$ Burian HM and Von Noorden GK: In Binocular vision and ocular motility, C. V. Mosby Co. 1980, p 297.

${ }^{14}$ Buckley E and Seaber JH: Dyskinetic strabismus as a sign of cerebral palsy. Am J Ophthalmol 1981 91: 652-7.

${ }^{15}$ Holman RE and Merritt JC: Infantile esotropia: Results in the neurologic impaired and 'Normal' child at NCMH (six years) J Paed Ophthalmol and Strab 1986 23: 41-4.

${ }^{16}$ Calcutt C: The use of contact lenses in the treatment of accommodative esotropia. Trans Fifth Int Orthop Congress 1984, 311-15.

${ }^{17}$ Parks MM: Ocular Motility and strabismus 1975, Harper \& Row, Hagerstown, Maryland.

${ }^{18}$ Mein J and Harcourt B: In Diagnosis and Management of ocular motility disorders, Blackwell Scientific Publications 1986b, 199.

${ }^{19}$ Goldstein JH: The role of miotics in strabismus, Surv Ophthalmol 1968 13: 31-46.

${ }^{20}$ Windsor CE: Surgically overcorrected esotropia: A study of its cause, sensory anomalies, fusional results and management. Am Orthop J 1968 16: 8-15.

${ }^{21}$ Dankner SR, Mash J, Jampolsky A: Intentional surgical overcorrection of acquired esotropia. Arch Ophthalmol 1978 96: 1848-52.

${ }^{22}$ Ruttum M and Von Noorden GK: Adaptation to tilting of the visual environment in cyclotropia $A m \mathrm{~J}$ Ophthalmol 1983 96: 229-37.

${ }^{23}$ Willshaw HE and O'Connor GM: Transposition surgery in childhood strabismus. Eye 1988 2: 41-3.

${ }^{24}$ Jampolsky A: Treatment of exodeviations in Paediatric Ophthalmology \& Strabismus Trans. New Orleans Academy Ophthalmol. 1986, p 201-34, C. V. Mosby.

${ }^{25}$ Hardesty HH, Boynton JR, Keenan PJ: Treatment of intermittent exotropia. Arch Ophthalmol 1978, 96: $268-74$.

${ }^{26}$ Pratt-Johnson JA, Barlow JM, Tillson G: Early surgery in intermittent exotropia. Am J Ophthalmology 1977, 84: 689-94.

${ }^{27}$ Caltrider $\mathrm{N}$ and Jampolsky A: Overcoming minus lens therapy for the treatment of intermittent exotropia. Ophthalmology 1983, 90: 1160-5.

${ }^{28}$ Hardesty $\mathrm{HH}$ : Prisms in the management of intermittent exotropia. Am Orthop J 1972, 22: 22-30.

${ }^{29}$ Jampolsky A: A simplified approach to strabismus diagnosis. Symposium on Strab. Trans. New Orleans Academy Ophthal 1971 p 66-75, Mosby, St Louis. 
${ }^{30}$ Srebro R: The visually evoked response: Binocular facilitation and failure when binocular vision is disturbed. Arch Ophthalmol 1978, 96: 839-44.

${ }^{31}$ Campos EC and Chiesi C: Binocularity assessed with visually evoked responses. Trans Fifth Int. Orthoptic Congress 1983, 415-20.

${ }^{32}$ Campos EC and Chiesi C: Binocularity in comitant strabismus: 11 Objective evaluation with visual evoked responses. Documenta Opthalmologica 1983, 55: 277-293.

${ }^{33}$ Shea SL, Aslin RN, McCulloch D: Binocular VEP summation in infants and adults with abnormal binocular histories. Invest Oph \& Vis Sci 1987, 28: 356-365.
${ }^{34}$ Fox R, Aslin RN, Shea SL, Dumais ST: Stereopsis in human infants. Science Reprint Series 1980, 207: 323-324.

${ }^{35}$ Archer SM, Helveston EM, Miller KK, Ellis FD: Stereopsis in normal infants and infants with congenital esotropia. Am J Ophthal 1986, 101: 591-596.

${ }^{36}$ Braddick O, Atkinson J, Juless B, Kropfe W, et al: Cortical binocularity in infants. Nature 1980, 288: 363-365.

${ }^{37}$ Rossiter LI: An evaluation of binocular visually evoked responses recorded to a dynamic random dot corelogram in normal BSV and comitant unilateral BSc thesis submission. 